\title{
Remix e sampling: identidades e memória dos DJs na música eletrônica'
}

\section{Remix and sampling: DJs' identity and memory in the electronic music}

\author{
Herom Vargas \\ Universidade Metodista de São Paulo \\ <heromvargas50@gmail.com>
}

\author{
Nilton Faria de Carvalho \\ Universidade Metodista de São Paulo \\ $<$ niltonblog@gmail.com>
}

\author{
Priscila Ferreira Perazzo \\ Universidade Municipal de São Caetano do Sul
} <prisperazzo2@gmail.com>

\author{
Como citar este artigo (How to cite this article): \\ VARGAS, Herom; CARVALHO, Nilton Faria de; PERAZZO, Priscila Ferreira. Remix e sampling: identidades e \\ memória dos DJs na música eletrônica. Revista Famecos, Porto Alegre, v. 25, n. 2, p. 1-18, maio, junho, julho e \\ agosto de 2018: ID28156. DOI: http://dx.doi.org/10.15448/1980-3729.2018.2.28156.
}

\section{RESUMO}

Este artigo versa sobre o uso das técnicas do sampling e do remix como parte dos processos criativos na música eletrônica que, em determinados casos, trazem memórias e identidades musicais dos DJs (discjóqueis). Por meio dos Estudos Culturais, a presente pesquisa investiga o hibridismo nas produções musicais de quatro DJs brasileiros: KL Jay (Racionais MC's), Alfredo Bello (DJ Tudo), Luana Hansen (DJ e MC) e Rodrigo Gorky (Bonde do Rolê e Fatnotronic) - cujas subjetividades são percebidas nos sampleamentos e/ou remixagens. A ideia é compreender como a memória musical proporciona ao disc-jóquei determinados elementos que articulam hibridismos na linguagem musical. Dessa forma, o aspecto fugidio das identidades desses artistas, que opera nas substâncias híbridas de suas canções, subverte padronizações e discursos hegemônicos na cultura midiática.

Palavras-chave: Música eletrônica. Memória. Identidade.

\section{ABSTRACT}

This research deals with the use of sampling and remix techniques as part of the creative processes in electronic music that, in certain cases, brings memories and musical identities. Based on Cultural Studies, this research investigates the hybridity in music productions made by four brazilian DJs: KL Jay (Racionais MC's), Alfredo Bello (DJ Tudo), Luana Hansen (DJ and MC) and Rodrigo Gorky (Bonde do Rolê and Fatnotronic) - whose subjectivities are noted in sampling using and/or remixing. The ideia is understand how musical memory provides to the disc jockey certain elements that articulate hybridities in the musical language. Thus, the fugitive aspect of these artists' identities, that operates on hybrid substances of their songs, subverts standardization and hegemonic discourses in media culture.

Keywords: Electronic music. Memory. Identity.

1 Este artigo provém de pesquisa financiada por bolsa de estudos CAPES. 


\section{Introdução}

O surgimento e o desenvolvimento de técnicas de gravação musical configuraram a canção como produto midiático ao longo do século XX. Sua estrutura musical e de letra, sua duração, a fidelidade sonora da gravação, a estabilização dos gêneros musicais, a instrumentação usada e as maneiras de escuta foram parâmetros da canção popular que se dinamizaram conforme os padrões de fixação do som nos vários suportes de gravação que se desenvolveram ao longo da primeira metade do século. Desde as primeiras gravações em cilindros e discos de cera, novos formatos de canção e distintas formas de audição musical reconfiguraram os cantos populares e sedimentaram gêneros musicais nos ambientes urbanos (Tatit, 2004; De Marchi, 2005). No final da década de 1920, os primeiros programas musicais ${ }^{2}$ são inseridos nas transmissões radiofônicas e, ao final da Segunda Guerra Mundial, a popularização do LP3 (ou álbum) e dos novos aparelhos de reprodução musical - toca-discos de vários tipos - intensificaram o consumo de canções por meio dos discos. 0 sucesso dos LPs como formato privilegiado, tanto para a indústria fonográfica como para o consumo doméstico, apontaram para o uso crescente do disco a ponto, inclusive, de possibilitar a organização de festas sem músicos in loco, nas quais as pessoas se reuniam para ouvir faixas gravadas. O responsável pelo repertório sonoro levado a esses encontros ficou conhecido como discjóquei (DJ). Na década de 1970, o DJ se tornou figura central no ambiente das discotecas, fato que aproximou alguns desses artistas a novas formas de colocar canções para tocar, alterando ajustes que modificavam esteticamente a música.

Assim como o artista experimental das vanguardas lidou com a dialética entre as formas estéticas tradicionais e as novas (Eco, 1970), nota-se na música pop o movimento de novos processos de produção musical. Emergem as versões $d u b$ dos coletivos sound system ${ }^{4}$, as remixagens da disco music e os experimentos musicais do grupo alemão Kraftwerk ${ }^{5}$. Outro fator significativo foi

2 Segundo White, Crisell e Principe (2009), o primeiro registro de programa musical em uma rádio ocorreu em 1927, apresentado pelo radialista Christopher Stone, na emissora britânica BBC. Stone tocava discos de jazz.

3 Long Play, capaz de armazenar um número maior (sobretudo em relação ao disco de 78 r.p.m). Geralmente é elaborado com um material plástico chamado vinil (feito de PVC).

4 Coletivos formados por disc-jóqueis, engenheiros de som e MCs (mestres de cerimônia) que popularizaram ritmos como ska, rocksteady e reggae. Os engenheiros Ruddy Redwood e King Tubby foram pioneiros nos experimentos com o dub (espécie de desdobramento eletrônico do reggae) na década de 1960, ao usarem ajustes de volume e omissão de vozes nas reedições de canções existentes. Outro artista fundamental é o músico e produtor Lee "Scratch" Perry, que montou o estúdio The Black Ark, onde usou a mesa de mixagem à semelhança de um instrumento.

5 Uma das primeiras apresentações do Kraftwerk ocorreu na cidade de Soest, na região oeste da Alemanha. O registro mostra a preocupação da banda em explorar sons até então pouco habituais na cultura pop. Disponível em: https://www.youtube.com/watch?v=Uv09NXOyOoU. 
o surgimento do sampler ${ }^{6}$, aparelho que possibilita a reprodução de trechos de materiais pré-gravados - atualmente também no formato de software -, que inseriu na atividade criativa dos disc-jóqueis do hip hop, com a prática cultural do sampling, a possiblidade de reutilização de fragmentos de outras canções na elaboração de novas músicas. Todos esses movimentos, cada qual à sua maneira, exerceram influência na produção musical eletrônica.

$\mathrm{Na}$ intertextualidade oferecida pelo uso do sampling surgem textos capturados pela memória provenientes, por um lado, de determinados repertórios individuais dos DJs e, por outro, dos acervos de música gravada que circulam nos ambientes midiáticos (discos, rádio, TV, festas familiares ou jovens, audições no ambiente doméstico etc.), espécie de memória da cultura musical midiática. Tal perfil artístico, que se configura na cultura remix, é determinante para alguns hibridismos percebidos na música eletrônica representantes de uma política criativa que difere dos padrões delimitados pela indústria fonográfica e, portanto, uma forma alternativa de produção geradora de novos sentidos da música nas mídias.

O presente artigo propõe considerar que na obra de alguns DJs a reutilização de textos na produção musical, por meio de remixagens e sampleamentos, e seu resultado intertextual, possuem relações com articulações de determinadas memórias e identidades musicais desses artistas. O perfil criativo de disc-jóqueis mais experimentais caracteriza-se pelo armazenamento de experiências culturais e, por meio da escuta, pela absorção da diversidade das músicas gravadas que povoam o ambiente midiático sonoro.

Com essa motivação, o caminho teórico da análise tem como base os Estudos Culturais e as metodologias de Memória e Narrativas Orais de Histórias de Vida combinados na análise dos hibridismos na linguagem musical e dos relatos de história de vida dos artistas. Este artigo provém de pesquisa que reuniu depoimentos de disc-jóqueis brasileiros que lidam com as técnicas do sampling e da remixagem na produção de significado nas mídias. Os artistas foram identificados na pesquisa de campo que incluiu audição de obras e idas a apresentações musicais. Considerou-se o critério de acessibilidade na escolha do corpus, pois foi necessário selecionar disc-jóqueis que pudessem conceder entrevistas longas, em razão do uso da metodologia de Narrativas Orais de

6 Aparelho que possibilita ao DJ usar "conteúdos midiáticos pré-existentes" (preexisting media content) (Gunkel, 2016, p. 17), que geralmente são "amostras de som retiradas de vinis, programas de rádio, tevê e/ou videogames, dentre tantas outras fontes sonoras" (Conter; Silveira, 2014, p. 48).

7 A reutilização de textos é prática recorrente nas artes em geral, mas alguns autores usam esse termo ao compreendê-la no cenário pós-industrial. Para Eduardo Navas (2012, p. 7), por exemplo, tratase de uma "cultura definida pela reciclabilidade e apropriação" (a culture defined by recyclability and appropriation). 
Histórias de Vida. Assim, o corpus será formado pelos DJs: KL Jay (Racionais MC's), Alfredo Bello (DJ Tudo), Luana Hansen (DJ e MC) e Rodrigo Gorky (Bonde do Rolê e Fatnotronic). Na nossa argumentação, teoria e conceitos serão desenvolvidos junto aos depoimentos dos DJs e às análises das suas obras e das particularidades da música eletrônica.

Sobre o uso de Narrativas Orais de Histórias de Vida em Comunicação, Priscila Ferreira Perazzo (2015, p. 125) escreve que os sujeitos que se recordam do passado "escolhem, a partir de quem são como sujeitos da história, o que querem relatar, contar e resgatar sobre si próprios e seu tempo". Tal caminho metodológico conduziu esta investigação ao universo cultural de pertencimento desses artistas, uma vez que, na complexidade do mundo contemporâneo globalizado, o fluxo de informações que estimula novos contatos opera constantes transformações nos sujeitos, até porque "à medida que os sistemas de significação e representação cultural se multiplicam, somos confrontados por uma multiplicidade desconcertante e cambiante de identidades possíveis" (Hall, 2014 , p. 12). Dessa forma, para compreender esse trajeto artístico que absorve variados textos (sons e trechos de músicas), os quatro DJs foram entrevistados em suas residências e/ou nos estúdios em que produzem suas obras e, por meio de narrativas orais, reconstruíram suas memórias apontando os caminhos musicais (vivências) pelos quais passaram.

Esse processo contínuo de construção identitária faz emergir no cenário musical outros meios de produção marginais que absorvem a pluralidade sonora das mídias na geração de obras de perfil híbrido que não podem ser fechadas nas padronizações de gênero musical frequentes na indústria fonográfica. Essa música, que reúne menções a outros textos em distintos rearranjos como em um processo sincrético de criação, possui, na substância de sua linguagem, as subjetividades de um artista experimental representante de uma nova ética produtiva com base na diversidade. Por esse motivo, este artigo irá abordar o processo criativo de quatro DJs por meio dos relatos dos próprios artistas, divididos em tópicos e, no decorrer dessas narrativas, as escolhas geradoras dos hibridismosserãoidentificadascomofrutodeidentidadesmusicaisemconstrução.

\section{O processo de escuta no lar}

No trabalho de um DJ a audição musical é fator estético determinante por antecipar o devir do perfil híbrido da canção produzida por esse artista. Antes de qualquer trabalho relacionado à produção musical o disc-jóquei experimenta vários contatos com o campo da canção, desde a infância, passando por diversas vivências que resultam em uma gama de textos a serem potencialmente 
reutilizados em razão de seu valor simbólico por conta das experiências de vida que traduzem.

A prática de audição musical dos DJs não se resume à do consumidor comum. Trata-se de uma escuta que idealiza novos modos de criação. Segundo Santos, que escreveu sobre os desafios enfrentados pelo compositor John Cage na captação dos sons mundanos, o papel da escuta, à luz do pensamento de Cage, ultrapassa as fronteiras estáveis e permite "pensar em uma escuta que compõe" (Santos, 2000, p. 64). A relação do DJ com a diversidade musical do ambiente midiático segue lógica parecida, pois à semelhança do artista de vanguarda que capturava sons no caos citadino, no início do século $X X$, 0 disc-jóquei assimila determinadas canções nas mídias à engrenagem do seu processo criativo.

No lar, os primeiros contatos com a música geralmente são marcados pela influência de membros da família. Sintonizar uma rádio, manter uma coleção de discos e assistir a programas televisivos são, de certo modo, mediações sugeridas por pessoas com as quais se tem grau de parentesco. A lembrança que eu tenho é da minha mãe ouvindo rádio AM. [...] as AMs tocavam músicas de artistas como Roberto Carlos, Beatles, Martinho da Vila e Phil Collins, não o Phil Collins solo, mas com o Genesis ${ }^{8}$, lembra KL Jay. Na rememoração, textos que continuam a fazer sentido no presente são acionados. Segundo Alfredo Bello, o DJ Tudo: [...] eu não lembro, mas minhas irmãs diziam que quando eu era bebê via muito Vila Sésamo. Eu adorava. [...] eu tenho o LP na minha coleção e ouço. É, é legal pra caramba, é dos irmãos Marcos Valle e tal.

Rodrigo Gorky cresceu rodeado pelos discos do pai, que também escutava a famosa Rádio Fluminense FM, cuja programação musical valorizava bandas de rock dos anos 1980. Nessa época, Rodrigo morava no Rio de Janeiro e convivia também com o imaginário da cidade que reivindicava espaço para um ritmo periférico que surgia na época, o funk carioca. A diversidade sonora encontrada hoje na obra do artista, como veremos mais adiante, passa por esses primeiros encontros sonoros vividos no passado. A Rádio Fluminense é uma rádio do Rio de Janeiro que explica as coisas mais inusitadas do mundo [...] Por exemplo, você já ouviu aquele Funk do Dermite, que eles sampleiam The Smiths [a faixa Bigmouth strikes again]? Você já parou para pensar por que os funkeiros do Rio samplearam aquilo? Porque existia essa rádio no Rio [...] tanto que no Rio de Janeiro era normal ser fã de Smiths naquela época, conta.

8 Todas as citações das entrevistas com os DJs estão grafadas em itálico. A relação de entrevistas está nas referências, ao final do artigo. 
A canção à qual Rodrigo se refere é Funk do dermite 9 . Divulgada na série de coletâneas Pancadão, em 2003, a faixa usa em sua estrutura um sample que reproduz o riff de guitarra da música Bigmouth strikes again (Smiths). O próprio título da canção, "dermite", é inspirado na fonética do nome do grupo britânico The Smiths. A intertextualidade gerada pelo sampling, portanto, inevitavelmente aciona questões subjetivas de representação por expor os desafios "para a compreensão dos imaginários sociais, sentidos de temporalidade, de pertencimento e identidade, embates geracionais, presença e apropriação de elementos midiáticos" (Pereira, 2015, p. 95).

A escuta musical na vida da DJ e MC Luana Hansen começou ambientada na discografia de música brasileira de seu tio Chico. Ele sempre ouviu disco, e era apaixonado por música popular brasileira. Lembro que ele tinha coleções completas de Gal Costa, de Maria Betânia, de Caetano, ela diz. Na obra recente de Luana, há raps que reúnem elementos de música brasileira, o que demonstra que a narrativa que resgata a convivência com o tio exerceu (e exerce) significativas influências no sentido impresso em seu trabalho. Para Jacques Le Goff (2003, p. 468), a "memória é um elemento essencial do que se costuma chamar identidade, individual ou coletiva, cuja busca é uma das atividades fundamentais dos indivíduos e das sociedades de hoje". Ou seja, rememorar é também falar sobre o agora, processo que reinterpreta o passado no presente articulado na ressignificação. Meu tio foi a maior referência. Ele vivia cantando pra mim uma música da Gal Costa [a canção Teco-teco] que até hoje eu falo que vou colocar no meu segundo disco como introdução, explica Luana.

Assim, mesmo que a prática da escuta musical obedeça a certa mediação no seio familiar, muitas dessas canções, materializadas nos fonogramas (faixas gravadas em discos e divulgadas pelo rádio), são assimiladas e recontextualizadas nos arquivos subjetivos da memória individual. Esses textos armazenados dividem espaço com outras fontes sonoras absorvidas no decorrer da vida dos DJs e, no controle do sampler, são retrabalhados. Em outras palavras, trata-se de "reorganizar o passado no presente, ressignificá-lo, retomando-o, juntando e incluindo cacos" (Conter; Silveira, 2014, p. 50).

9 Cantada pelo MC Saquinho, a faixa também aparece com o título Montagem dermite em algumas coletâneas. Disponível em: https://www.youtube.com/watch?t=12\&v=QIMb9J3gOX8. 


\section{Discografia, festas e aprendizado musical}

O conhecimento musical de um DJ chega a outro patamar no momento em que o artista entra em contato com o mundo extrafamiliar. $O$ que antes era restrito ao lar, agora sofre também influência dos amigos, dos eventos musicais e das informações que fluem da diversidade textual midiática. A maturidade musical dos DJs entrevistados é percebida no ato de colecionar discos, acervos geralmente compostos por LPs, aqui pensados não apenas como produtos midiáticos, mas também como objetos pertencentes à família e que detêm lembranças sociais (Le Goff, 2003).

Alfredo Bello viaja por diferentes regiões do Brasil e do mundo em busca de canções de culturas locais para a elaboração de seu trabalho. Os samples inseridos em seus discos, em especial no álbum Pancada motor - manifesto da festa ${ }^{10}$ (2014), são fragmentos de gravações que o artista fez de diversos músicos locais. Também aproveitou as viagens para ampliar sua coleção de discos atualmente possui treze mil LPs. Trouxe coisas da Martinica e do Caribe em geral, Turquia. [...] Tenho contato com muita coisa, música da Tunísia, que eu nunca tinha conseguido eu encontrei lá no Marrocos, acabei trazendo muitos compactos, destaca o DJ. Essas experiências são potencializadas quando somadas às memórias musicais do artista. Durante a juventude, suas principais influências foram grupos de punk rock e pós-punk: O primeiro disco que comprei foi o London Calling (The Clash), gostava muito do Closer (Joy Division) e do Bauhaus também. [...] The Stooges foi outra banda que marcou muito, ele lembra.

A coleção de discos, nesse caso, desempenha papel importante, semelhante ao dos objetos detentores de memórias, mais do que uma coleção de fonogramas. Para Ecléa Bosi, os objetos que estão organizados no ambiente do lar - como a coleção de discos - estabelecem uma linguagem relacional com a personalidade dequemos possui, pois"nesse conjuntoamamosa condiçãotácita, mas eloquente. Mais que uma sensação estética ou de utilidade eles nos dão um assentimento à nossa posição no mundo, à nossa identidade" (Bosi, 2003, p. 25).

O rock foi uma das primeiras apropriações estéticas da memória musical de Luana, que costumava andar pelas ruas do bairro paulistano de Pirituba com uma camiseta do grupo Rage Against the Machine. Entretanto, o imaginário coletivo do local onde vivia refletia-se no gosto da maioria dos jovens pelo rap como principal ritmo musical. Não à toa nomes importantes da cena hip hop paulistana surgiram na região, como o grupo RZO. Eles [o grupo RZO] andavam aqui na quebrada, faziam shows na quebrada. Dina Di, RZO e Sabotage. Era o que

10 No teaser do álbum é possível conferir a característica intertextual do trabalho. Disponível em: https://www.youtube.com/watch?v=CXHkN5fe18g. 
tocava. Por todos os lugares que eu andava tocava Sabotage e RZO, recorda Luana. Seu encontro com o rap, portanto, pode ser entendido à luz das significações dos imaginários coletivos como "mobilizadores dos comportamentos sociais" (Laplantine; Trindade, 1997, p. 6).

A relação de KL Jay com a música ganhou novos desdobramentos quando o DJ passou a frequentar as lojas de discos no Centro de São Paulo, durante a juventude. Lembro de ir ao Centro [de São Paulo] com um colega de bairro mais velho que eu, que também gostava de música [...] Ele comprou o disco do Zapp que tem a [faixa] More bounce to the ounce e também a lt's gonna be alright, diz. Nessa época, KL Jay conheceu diversas bandas do funk norte-americano, o que trouxe o contato com vertentes sonoras diferentes das que geralmente eram transmitidas nas programações das rádios que sua mãe ouvia em casa.

Diferente da discografia composta por discos de rock de seu pai, Rodrigo Gorky se aproximou do pop no período da adolescência. As leituras da revista Bizz Letras Traduzidas e as discussões sobre música com os amigos do condomínio onde morava, em Juiz de Fora (MG), foram os principais norteadores das preferências do DJ nesse período, como destaca Rodrigo: $A$ gente começou a fazer festa hi-fi [nas quais o anfitrião é responsável pela música tocada] na casa das pessoas [...] como eu era o menino que tinha os discos e gravava as músicas das rádios em fita, eu sempre tocava. Eu tocava muito Roxette e muita trilha internacional de novela. O protagonismo de Rodrigo à frente das festas do período da adolescência indica o caminho artístico seguido por ele como DJ. Já o contato com a diversidade musical posteriormente é ampliado na web e sua "infinita jukebox"11 (Reynolds, 2011, p. 54), que permite ao DJ selecionar canções entre milhares de possibilidades.

O que este tópico da pesquisa procurou demonstrar é que o contato dos disc-jóqueis com a diversidade musical vem de diferentes fontes. Como escrevera Halbwachs (1990, p. 170) em reflexão sobre a memória do músico: "um músico experimentado, e que tenha executado um grande número de peças diferentes, será como alguém que leu muito". É justamente esse campo complexo e diverso que trataremos no próximo item, no qual se organiza uma política artística que reivindica pluralidade rítmica nas mídias.

11 "infinite jukebox". 


\section{Memória e identidades musicais por meio de sampleamentos e remixagens}

A trajetória de vida que colocou os DJs em contato com variados fluxos musicais é materializada nas produções desses artistas. O movimento que identifica e seleciona determinado material pré-gravado para reutilizá-lo em uma nova obra coloca em jogo a representatividade simbólica do texto retrabalhado, cuja importância ultrapassa sua própria característica estéticosonora. O sampling e a remixagem funcionam como mediadores entre a diversidade musical armazenada na memória dos DJs e a substância da canção que será elaborada.

O perfil híbrido que emerge desse processo implode as delimitações de gênero musical formatadas sob a lógica mercadológica - que padroniza para oferecê-lo como produto -, pois como escreve Vargas (2007, p. 23):

Por incorporar o dialogismo e ser polifônico por excelência, o hibridismo é um processo selvagem de rompimento com as estabilidades teóricas e com as esperanças de unicidades semânticas; mas, ao mesmo tempo, mostra-se docemente criativo por trazer em si, potencialmente, os germes de novas alternativas para as mais assustadoras combinações.

No caso dos DJs, o sampleamento e a remixagem, combinados a partir da predisposição do artista à mistura sonora, estabelecem uma ética alternativa de criação musical que modifica as formas de produção. A linguagem intertextual fundada na colagem digital de sons reconfigura o uso dos materiais prégravados. Se, segundo Williams (1988, p. 156), as estruturas do sentir "podem ser definidas como experiências sociais em solução"12, o caso dos DJs pode ser pensado como experiências sociais que demarcam processos formativos que alteram concepções consideradas acabadas na música popular. A canção gravada se torna uma obra aberta, inacabada, no trabalho dos disc-jóqueis.

Para Gomes (2011, p. 31), na obra de Williams, "às modificações na vida e no pensamento correspondem a alterações na linguagem e, desse modo, é possível verificar como certas palavras adquiriram novos sentidos" - mudanças que acompanham novas configurações sociais. A produção de sentido na linguagem musical produzida pelos DJs entrevistados, portanto, será tratada como uma ressignificação similar. Até porque a cultura remix "desenvolve-se no movimento de colaboração, tomar algo que já existe e transformá-lo em algo novo por meio da interpretação pessoal"13 (Navas, 2012, p. 60). Trata-se de uma

12 No original: "pueden ser definidas como experiencias sociales en solución."

13 "Remix culture thrives on the drive to collaborate, to take something that already exists and to turn it into something new by way of personal interpretation". 
modificação inclusive nos discursos da cultura midiática porque a autoridade do autor citado, que geralmente possui certo status discursivo dentro de uma sociedade ou cultura (Foucault, 1998, p. 211), também é reinterpretada.

Quando Rodrigo Gorky, Pedro D'Eyrot e Marina Vello montaram o Bonde do Rolê, em 2005, o grupo gravou o disco Baterias do poder. A produção musical trabalhada por Rodrigo reúne aspectos de suas primeiras experiências de escuta musical, como o uso de batidas de funk e samples de bandas de rock. Na faixa Dança da ventoinha ${ }^{14}$, por exemplo, Marina e Rodrigo cantam à semelhança dos MCs do funk carioca - a abordagem sexual das letras funciona inclusive como um pastiche do ritmo -, cuja base instrumental foi sampleada da canção $I$ believe in a thing called love, do grupo inglês The Darkness. O [álbum] Baterias do poder é por causa dos power drums [estilo da bateria], sabe? Esses hard rocks dos anos 1980, por isso o disco se chama Baterias do poder [...] por isso sampleamos o Darkness, lembra Rodrigo.

Após fazer parte do trio feminino de rap A TAL, Luana decidiu aprender também técnicas de produção musical para ter mais autonomia sobre suas composições e poder se apresentar como artista solo. Estudou sonoplastia na SP Escola de Teatro, leu diversos tutoriais sobre produção e conseguiu montar seu home studio. Lembro que quando eu falava que queria ter um par de pick-ups [tocadiscos usados por DJs] o que eu ouvia era: "nunca você vai conseguir comprar"... Quando eu dizia que queria ser produtora, diziam: "você nunca vai conseguir produzir, é muito difícil", ela ressalta, uma vez que a mulher DJ geralmente encontra maiores obstáculos do que os homens no cenário musical. Segundo Gavanas e Reitsamer (2013, p. 58), as mulheres DJs "não são vistas como figura normativa de autoridade"15. Além disso, outro motivo para a cristalização desse tipo de discurso, de acordo com as autoras, é que as mulheres frequentemente não são associadas ao interesse por tecnologia. A autonomia artística adquirida por Luana Hansen assume significado político em diversas frentes, como a produção musical independente e a temática de seus raps, que abordam o feminismo, a mulher negra na sociedade e os direitos LGBTs.

O uso do sampler e a prática do sampling, entretanto, agregam outros posicionamentos de Luana em relação mundo, como na canção Samba Brasil ${ }^{16}$, faixa em que sampleou a música Saudosa maloca, de Adoniran Barbosa. Fui criada com o meu tio e ele ouvia MBP. Ele falava que o Adoniran era um sambista paulista, que o samba dele falava sobre São Paulo [...] Epor ele serpaulista, não tinha como, eu sou paulista, tem aquela coisa de valorizar os nossos artistas, diz a DJ.

14 Disponível em: https://www.youtube.com/watch?v=rfd6qC_G7mo.

15 "[they] are not seen as the normative figure of authority".

16 Disponível em: https://www.youtube.com/watch?v=r2tQMbshqUc. 
O sample selecionado da canção do sambista Adoniran Barbosa, recontextualizado no rap de Luana, além de acionar variantes estéticas que caracterizam a linguagem híbrida, também reforça aspectos identitários na obra da rapper. Afinal, o sambista paulistano notabilizou-se cronista de lugares tradicionais de São Paulo, como o bairro do Brás e o trem que transporta a população da cidade. O significado gerado pelo sampleamento, desse modo, caracteriza Luana também como narradora do cotidiano ao seu redor, uma vez que a artistas traz em suas letras e videoclipes citações ao bairro de Pirituba e à estação homônima.

Dos DJs entrevistados, Alfredo Bello possui uma forma diferente de usar o sampler. No lugar de reutilizar trechos de canções existentes, o disc-jóquei identifica artistas de culturas populares, grava esses músicos locais e depois usa samples desses arquivos nas suas produções. Nas apresentações ao vivo, no entanto, Alfredo se apresenta com uma banda composta por instrumentação tradicional (baixo, guitarra, naipes de sopro e bateria) e também leva ao palco seu computador, com o qual aciona samples durante as canções executadas. Assim, a performance ao vivo propõe a "releitura de uma configuração em outra, ou seja, vozes e instrumentos irão traduzir novamente os samples e outros elementos combinados no ambiente do estúdio" (Vargas; Carvalho, 2016, p. 64).

Em uma de suas viagens pelo Brasil, Alfredo encontrou o grupo de cultura baianá17 Baianas de Barreiras. Da gravação registrada pelo DJ durante a visita, foi selecionado o loop percussivo - sample de curta duração acionado de forma repetida - usado na faixa É hoje é hoje ${ }^{18}$, de seu último álbum. Encontrei o grupo no dia 23 de junho de 2009, eu lembro o dia. Fui ao Povoado de Barreiras e gravei com eles, com a Maria Padeira, que é mestre de baianá lá [...] Então a minha relação com eles é muito forte, já voltei lá umas três, quatro vezes para festar com elas, para levar os discos e mostrar a elas. A essas experiências somam-se outras vivências musicais de Alfredo que transitam nos campos da música eletrônica e do rock, como na canção Meu natural ${ }^{19}$, cuja linguagem traz riffs de guitarra combinados com instrumentos percussivos de cultura popular por meio de softwares de edição musical. Existe realmente uma referência de guitarra de música punk, e a batida é de música popular, não mexi em nada [...] É uma caixa, uma zabumba e um ganzá, a gente imagina que é muita coisa, mas na verdade é bem simples, a gente deu uma trabalhada boa na mixagem, explica o artista. Assim, a linguagem

17 De origem baiana, essa cultura atualmente está espalhada em diferentes estados brasileiros. Sua formação conta com uma mestra e envolve instrumentação e dança. O som elaborado por grupos de cultura baianá possui forte presença de instrumentos de percussão, como ganzá e zabumba.

18 Disponível em: https://www.youtube.com/watch?v=TghCdjgMSmg.

19 Disponível em: https://www.youtube.com/watch?v=C4D89CmqNQo. 
musical elaborada pelo DJ possui relação com uma formação artística construída com "princípios de rebeldia e princípios de conservação da identidade"20 (Sarlo, 2007, p. 19).

No álbum Sobrevivendo no inferno (1997), do grupo Racionais MC's, as produções de KL Jay resultam dos processos de escuta assimilados pelo DJ no decorrer de sua vida. Na canção Fórmula mágica da paz ${ }^{21}$, o disc-jóquei sampleou ${ }^{22}$ a base instrumental da faixa It's gonna be alright ${ }^{23}$, do grupo soul-funk Zapp, canção com a qual KL Jay entrou em contato na juventude, no período em que visitava lojas de discos no Centro de São Paulo com os amigos. O contato com a música da banda norte-americana no passado surgiu como componente estético de sua produção pelo fato de seu significado continuar a integrar seu universo de pertencimento, uma vez que a "memória do tempo passado terá um efeito direto sobre as representações de identidade" (Candau, 2014, p. 85).

Na elaboração de Periferia é periferia, o DJ do grupo Racionais MC's propõe citações mais complexas ao samplear canções de diversos rappers ${ }^{24}$ de regiões periféricas do Brasil. Acontecia muito nos raps norte-americanos, o fato de eles usarem trechos de outros raps, para soar como se aquele MC do outro grupo estivesse fazendo uma participação ali, do nada [...] Você resgata a música, trechos de músicas, que as pessoas até já esqueceram. Uma espécie de arranjo, um arranjo vocal. Só o hip hop fazisso, é muito autêntico. Então eu quis fazerigual também, igual ao que eles lá [nos EUA] faziam. Foram boas frases ali, usei o Sistema Negro, o GOG, o próprio Racionais [...] parece mágica, mas é um arranjo que você faz com o tocadiscos. Entretanto, na mesma canção o DJ usa como base instrumental um sample da canção Cannot find a way, do guitarrista norte-americano Curtis Mayfield, que ressignifica a canção como ambiente de negociação identitária, em que artistas independentes dividem espaço com um músico detentor de êxito global.

O período que antecedeu o lançamento do álbum Tropicalbacanal (2012), do Bonde do Rolê, marcou o interesse de Rodrigo Gorky pelo trabalho de artistas brasileiros. Meu lado colecionador de discos foi crescendo cada vez mais, e fui pesquisando sobre música brasileira e etc. [...] eu queria que o disco fosse mais tropical, mais brasileiro e mais bonito, por assim dizer, comenta o artista. Mas, na mesma época, Rodrigo também havia conhecido o trabalho da cantora

20 "principios de rebeldía y principios de conservación de la identidad".

21 Disponível em: https://www.youtube.com/watch?v=ZrPla4-7aSl.

22 O sample do grupo Zapp aparece na versão divulgada antes do lançamento oficial do álbum Sobrevivendo no inferno. Já a versão inserida no disco usa sample da canção Attitudes (The Bar-Kays).

23 Disponível em: https://www.youtube.com/watch?v=CMkjDQKoMKc.

24 Os raps sampleados são: SL (Um Dependente) (MRN); Brava gente e Por um triz (Thaide \& DJ Hum); Bem vindos ao inferno e Cada um por si (Sistema Negro); Brasília periferia (GOG); Homem Na Estrada e Fim De Semana no Parque (Racionais MC's). 
rockabilly Wanda Jackson, em razão de uma coletânea do grupo The Cramps. Aprendi sobre Funnel of love [da Wanda Jackson] por conta de uma coletânea do Cramps, que tem uns onze volumes, a Songs the Cramps taught us, que é uma coisa que eu estava ouvindo muito na época, ele acrescenta. Esses encontros rítmicos foram materializados na canção Kilo ${ }^{25}$, que usa um riff de guitarra sampleado da canção Funnel of love ${ }^{26}$, batidas sintéticas de funk e vocais pop.

A música de linguagem híbrida produzida pelos DJs entrevistados é um desdobramento de vivências à luz da diversidade rítmica globalizada. Pablo Vila (1996, p. 5) considera que o som e as letras da música popular "oferecem maneiras de ser e de se comportar"27, modos de representação construídos notadamente na escuta musical. Por exemplo, Rodrigo Gorky ampliou seu conhecimento sobre música brasileira no período que antecede a gravação do álbum Tropicalbacanal, aspecto que marcou também seu trabalho no Fatnotronic, projeto idealizado com o DJ Phillip A., em 2014. Eu pensei: "vamos fazer isso aqui, com música brasileira, porque eu estou cheio de coisas [discos] de música brasileira", explica. A dupla atualmente remixa canções de artistas como Banda Black Rio, Tim Maia, Marcos Valle, Astrud Gilberto, entre outros. Mesmo modificadas, as faixas são portadoras de valor simbólico, pois o remix é "dependente da história para ser eficaz"28 (Navas, 2012, p. 74).

\section{Considerações finais}

Entende-se que o resultado expresso na canção híbrida é fruto de um processo, aqui narrado por seus próprios produtores, porém, representativo de algo maior. A característica emotiva do relato "remete às representações que fazem os membros de um grupo sobre sua identidade e sua história" (Candau, 2014 , p. 87). A linguagem musical que nasce de sampleamentos e remixagens é um espaço de negociação de identidades musicais construídas a partir de uma escuta nômade de rumo impreciso devido à sua constante alternância (Santos, 2000, p. 68). Por esse motivo, essas canções diferem da estabilidade semântica típica das canções massivas de sucesso, pois nascem de processos de experimentação em home studios, hibridizadas, para divulgação em mídias paralelas às do mainstream.

Tais movimentações são marcas de um perfil artístico específico, identificado pelas narrativas orais de histórias de vida, nas quais a pluralidade de

25 Disponível em: https://www.youtube.com/watch?v=wPqGoeLUZ_w.

26 Disponível em: https://www.youtube.com/watch?v=BXV19NfP3hA.

27 "ofrecen maneras de ser y de comportarse".

28 No original: "dependent on history to be effective". 
identidades se refletiu em sua complexidade. Há uma predisposição à mistura nessas construções musicais e identitárias que remete ao conceito de diferença, trabalhado por Stuart Hall (2003, p. 76):

[...] o adolescente negro que é um DJ de um salão de baile toca jungle music mas torce para o Manchester United; ou o aluno muçulmano que usa calça jeans larga, em estilo hip-hop, de rua, mas nunca falta às orações da sexta-feira, são todos, de formas distintas, "hibridizados". Se eles retornassem a suas cidadezinhas de origem, o mais tradicional deles seria considerado "ocidentalizado" - senão irremediavelmente diasporizado. Todos negociam culturalmente em algum ponto do espectro da differance, onde as disjunções de tempo, geração, espacialização e disseminação se recusam a ser nitidamente alinhadas.

A reorganização do sentimento de pertencimento dos sujeitos, nos processos de globalização, é percebida também nos caminhos estéticos dos DJs. A memória musical desses produtores, espaço de cruzamento de matrizes simbólicas e de vários códigos (García Canclini, 1995), deixa fluir, por meio dos relatos, um ambiente já hibridizado antes mesmo de se tornar linguagem musical. Esse perfil é a grande problemática para os sistemas padronizadores do ambiente midiático, pois nota-se que qualquer preocupação em delimitar fronteiras se perderia frente à intertextualidade dessas produções.

Sampleamentos e remixagens transformam enquadramentos estéticos em obras rizomáticas, rebeldes em sua cambiante produção de sentido. A articulação do rizoma, para Gilles Deleuze e Félix Guattari (2000, p. 24), ocorre quando "um traço intensivo começa a trabalhar por sua conta, uma percepção alucinatória, uma sinestesia, uma mutação perversa, um jogo de imagens se destacam e a hegemonia do significante é recolocada em questão".

O presente estudo analisou os hibridismos gerados por sampleamentos e remixagens no trabalho de quatro DJs. A combinação teórica de Estudos Culturais e metodologias de Memória e de Narrativas Orais de Histórias de Vida ampliou a investigação ao trazer uma abordagem da linguagem capaz de jogar luzes sobre a subjetividade dos artistas criadores.

Identificou-se um tipo de canção que nasce de novos meios de produção musical e que utiliza conteúdos pré-gravados para criar canções híbridas. Obras concebidas em pequenos estúdios domésticos, cuja inovação está na ressignificação do papel da música gravada - uma vez que ela passa a ser também elemento estético passível de apropriação. Tal ideia remete à preocupação de Raymond Williams (1988) com a mudança de aspectos culturais do passado no presente, este último entendido pelo autor como ambiente de leitura crítica e novos processamentos perceptivos. 
O sampler, enquanto ferramenta, e as técnicas do sampling e da remixagem, como estratégias e procedimentos culturais de criação, são mediadores de trajetórias devidaassimiladoras deidentidadesmusicaisquenecessitamnegociar espaços mais diversos no ambiente midiático contemporâneo. Entretanto, samplear e remixar são paradoxais: de um lado, reivindicam a diversidade nas mídias, ao promoverem hibridismos e darem campo aos exercícios criativos dos DJs; de outro, também podem reiterar textos canônicos da cultura midiática, de artistas que possuem ampla circulação nos fluxos globais.

Mashácasos de subversão dos discursoshegemônicos nos sampleamentos. No rap Periferia é periferia, o sampling equipara o valor simbólico de produções alternativas locais com o de uma obra mundialmente conhecida quando $\mathrm{KL}$ Jay insere na mesma linguagem samples de rappers brasileiros (Thaíde, GOG e Sistema Negro) e um sample do guitarrista soul Curtis Mayfield.

DJ Tudo, que grava os próprios samples em seus encontros com culturas populares, propõe outra política afirmativa minoritária. O sample que evoca o grupo Baianas de Barreiras estabelece novos cânones nas mídias, ao desterritorializar esses artistas locais e colocá-los nos fluxos globais por meio de plataformas na web ou nas turnês internacionais do DJ.

Investigações futuras podem trabalhar com a hipótese de uma terceira possibilidade, em resposta ao binarismo mainstream/underground, pois até mesmo cânones da cultura midiática abandonam suas posições para acionarem misturas inusitadas - como quando o baixista Flea, do grupo Red Hot Chili Peppers, gravou um vídeo ${ }^{29}$ tocando baixo sobre uma canção do MC Guimê. São textos que já nascem de significações ciborgues, um híbrido de tecnologia e subjetividade que poderia ser considerado um novo momento na criação artística contemporânea, em que uma política produtiva minoritária transcende para um estágio de pós-sampleamento e pós-remixagem, no qual o âmago da linguagem é a própria diversidade.

\section{REFERÊNCIAS}

BOSI, Ecléa. O tempo vivo da memória: ensaios de psicologia social. São Paulo: Ateliê Editorial, 2003.

CANDAU, Joël. Memória e identidade. São Paulo: Contexto, 2014.

29 Disponível em: https://www.youtube.com/watch?v=yl_rZzShuW8. 
CONTER, Marcelo Bergamin; SILVEIRA, Fabrício Lopes da. Sampleamento de imagens sonoras em Fear of a Black Planet. Revista Resonancias, Santiago de Chile, v. 19, n. 35, p. 47-60, 2014. Disponível em: http://resonancias.uc.cl/images/ PDFs_n_35/conter_lopes_sampleamento.pdf. Acesso em: 04 mai. 2017. http://dx.doi.org/10.7764/res.2014.35.4.

DE MARCHI, Leonardo. A angústia do formato: uma história dos formatos fonográficos. Revista E-Compós, Brasília, v. 2, 2005. Disponível em: http://www.compos.org. br/seer/index.php/e-compos/article/view/29/30. Acesso em: 20 abr. 2011.

DELEUZE, G; GUATTARI, F. Mil platôs: capitalismo e esquizofrenia, v. 1. São Paulo: Editora 34, 2000.

ECO, Umberto. La definición del arte. Barcelona: Martínez Roca, 1970.

FOUCAULT, Michel. Aesthetics, method, and epistemology. New York: The New Press, 1998.

GARCÍA CANCLINI, Néstor. Consumidores y ciudadanos conflictos multiculturales de la globalización. Miguel Hidalgo: Grijalbo, 1995.

GAVANAS, Anna; REITSAMER, Rosa. DJ technologies, social networks and gendered trajectories in european DJ cultures. In: ATTIAS, B. A.; GAVANAS, A.; RIETVELD, $H$. C. (edits.). DJ culture in the mix: power, technology, and social change in electronic dance music. London: Bloomsbury Academic, 2013.

GOMES, Itania Maria Mota. Raymond Williams e a hipótese cultural da estrutura de sentimento. In: GOMES, I. M. M.; JANOTTI JR, J. (orgs.). Comunicação e estudos culturais. Salvador: Edufba, 2011.

GUNKEL, David J. Of remixology: ethics and aesthetics after remix. London: MIT Press, 2016.

HALL, Stuart. A identidade cultural na pós-modernidade. Rio de Janeiro: Lamparina, 2014.

Da diáspora: identidades e mediações culturais. Belo Horizonte: UFMG, 2003.

HALBWACHS, Maurice. Memória coletiva. São Paulo:Vértice, 1990.

LAPLANTINE, François; TRINDADE, Liana. O que é imaginário. São Paulo: Brasiliense, 1997.

LE GOFF, Jacques. História e memória. Campinas: Unicamp, 2003.

NAVAS, Eduardo. Remix theory: the aesthetics of sampling. New York: Springer-Verlag/ Wien, 2012. 
PERAZZO, Priscila Ferreira. Narrativas orais de histórias de vida. Revista Comunicação \& Inovação. São Caetano do Sul, v. 16, n. 30, p. 121-131, 2015. Disponível em: http://seer.uscs.edu.br/index.php/revista_comunicacao_inovacao/article/ view/2754/1672 Acesso em: 14 ago. 2015.

PEREIRA, Simone Luci. Temos nosso próprio tempo: memória, temporalidade, consumo e imaginários juvenis sobre a década de 1980. In: ROCHA, R. M.; PERES-NETO, L. (orgs.). Memória, comunicação e consumo: vestígios e prospecções. Porto Alegre: Sulina, 2015.

REYNOLDS, Simon. Retromania: pop culture's addiction to its own past. London: Faber and Faber, 2011.

SANTOS, Fátima Carneiro dos. Música das ruas: o exercício de uma escuta nômade. Revista Opus. São Paulo, v. 7, p. 62-71, set. 2000.

SARLO, Beatriz. Tiempo passado. Cultura de la memoria y giro subjetivo. Uma discusión. Buenos Aires: Siglo XXI Editores Argentinos, 2007.

TATIT, Luiz. O século da canção. São Paulo: Ateliê Editorial, 2004.

VARGAS, Herom; CARVALHO, Nilton F. de. DJTudo, samples e hibridismos: da linguagem do estúdio para a apresentação ao vivo. Líbero. São Paulo, v. 19, n. 38, p. 59-68, 2016. Disponível em: http://seer.casperlibero.edu.br/index.php/libero/article/ view/800/790. Acesso em: 5 jun. 2017.

VARGAS, Herom. Hibridismos musicais de Chico Science \& Nação Zumbi. Cotia (SP): Ateliê Editorial, 2007.

VILA, Pablo. Identidades narrativas y música. Una primera propuesta para entender sus relaciones. TRANS Revista Transcultural de Música - Transcultural Music Review. Barcelona, n. 2, p. 1-26, 1996. Disponível em: http://www.sibetrans.com/ trans/articulo/288/identidades-narrativas-y-musica-una-primera-propuestapara-entender-sus-relaciones\#top. Acesso em: 23 set. 2015.

WHITE, Phil; CRISELL, Luke; PRINCIPE, Rob. On the record. New York: St. Martin's Press. 2009.

WILLIAMS, Raymond. Marxismo y literatura. Barcelona: Península, 1988.

\section{Entrevistas}

Kleber Geraldo Simões (KL Jay), por Nilton Faria de Carvalho, 25 jul. 2015, São Paulo.

Luiz Alfredo Coutinho (DJ Tudo), por Nilton Faria de Carvalho, 19 jul. 2015, São Paulo.

Luana Hansen, por Nilton Faria de Carvalho, 16 jun. 2015, São Paulo. 
Rodrigo Pereira Antunes (Rodrigo Gorky), por Nilton Faria de Carvalho, 30 jun. 2015, São Paulo.

Recebido em: 4/8/2017

Aceito em: 25/10/2017

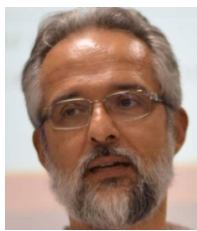

Dados dos autores:

Herom Vargas | heromvargas50@gmail.com

Professor do Programa de Pós-Graduação em Comunicação da Universidade Metodista de São Paulo

(UMESP) e doutor em comunicação e semiótica (PUC-SP).

Universidade Metodista de São Paulo (UMESP)

Endereço do autor:

R. Alfeu Taváres, 149 - Rudge Ramos.

09641-000 - São Bernardo do Campo, SP - Brasil.

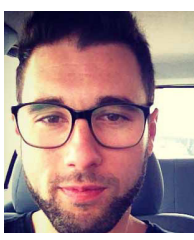

Nilton Faria de Carvalho | niltonblog@gmail.com

Doutorando no Programa de Pós-Graduação em Comunicação da Universidade Metodista de São Paulo -

UMESP.

Universidade Metodista de São Paulo (UMESP)

Endereço do autor:

R. Alfeu Taváres, 149 - Rudge Ramos.

09641-000 - São Bernardo do Campo, SP - Brasil.

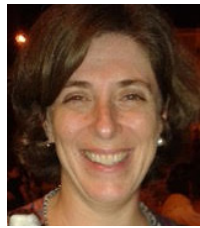

Priscila Ferreira Perazzo | prisperazzo2@gmail.com

Professora do Programa de Pós-Graduação em Comunicação - Mestrado Profissional da Universidade

Municipal de São Caetano do Sul (USCS). Doutora em História (USP).

Universidade Municipal de São Caetano do Sul - USCS

Endereço da autora:

Av. Goiás, 3400 - Campus Barcelona.

09550-051 - São Caetano do Sul - SP, Brasil. 